\title{
University student perceptions of the current and future role of nuclear energy in the world
}

\author{
R. L. Mahler ${ }^{1} \&$ M. E. Barber ${ }^{2}$ \\ ${ }^{I}$ Soil Science Division, University of Idaho, Moscow, Idaho, USA \\ ${ }^{2}$ Department of Civil and Environmental Engineering, \\ Washington State University, USA
}

\begin{abstract}
The purpose of this paper is to document university student perceptions of the role and viability of nuclear energy in the world. Nuclear energy perceptions of 6,330 students at the University of Idaho (Moscow, ID, USA) were measured between 1993 and 2012. As part of a learning assessment study students in the large freshman environmental science class were asked several questions about the environment in a standardized survey on both the first and last day of class. In this way changes in student perceptions as a result of the course could be quantified. The two specific nuclear energy statements contained in the survey were: (1) "Nuclear power is a serious problem from an environmental standpoint;" and (2) "Nuclear energy is preferable to the use of fossil fuels." In general $46.7 \%$ of students considered nuclear power a serious problem at the beginning of the course; however, at the end of the term less than $32 \%$ of students still held their initial negative opinion. In addition, a majority of students changed from indicating that fossil fuels were preferable to nuclear energy at the beginning of the course to a significant majority favoring or at least saying that nuclear power was no worse than fossil fuels at the conclusion of the term. Student major, year in college, gender and the year students were surveyed also had an impact on student answers. The significant finding of this study is that once students were educated in an unbiased way - including both the pros and cons of using nuclear energy they were more receptive to view the nuclear power option more favourably.
\end{abstract}

Keywords: public opinion, student perceptions, nuclear energy concerns, nuclear energy as an option, nuclear education. 


\section{Introduction}

Many scientists believe that global climate change is the most important environmental issue-facing planet Earth. The threat of catastrophic climate change will require rapid decarbonization of the world's current energy systems making renewable energy sources an important option [1]. Compared to coal, oil and natural gas, nuclear power results in low carbon emissions and consequently may be important in the mitigation of the adverse effects of global warming and climate change [2]. China and the USA, the two largest sources of global carbon dioxide emissions, are currently promoting nuclear power as a necessary response to global climate change [3]. Many agree that nuclear power is a viable option to control global greenhouse gas emissions; however, future development and utilization of the nuclear option will require both public acceptance and cooperation [4].

The risks of nuclear power became a public worry in the 1970s. The accidents at Three Mile Island (1979) and Chernobyl (1986) reinforced this concern (1). Some of these fears waned in the following two decades; however, the Fukushima accident (2011) again sharply increased public concern about the safety and vulnerability of nuclear reactors [5]. Public acceptance, perceptions and trust were more negative toward nuclear power after this accident than before [6]. Despite these accidents and associated concerns the major issue is do the climate and energy security benefits of nuclear power outweigh its risks and costs $[2]$ ?

In the mid-1970s $20 \%$ of Americans opposed nuclear power; however, the opposition to nuclear power grew to almost $60 \%$ by the early 1980 s [7]. The change in attitude to nuclear energy is assumed to originate from enhanced understanding [8]. Consequently, after the TMI and Chernobyl accidents, activities for public acceptance were enhanced. Factors including good performance, energy/electricity supply concerns in the early 2000s, more outspoken support by leaders in government and industry and media attention to the nuclear renaissance has boosted public support for nuclear energy in the last decade [9]. By 2003, 64\% of the public in the USA favored the use of nuclear power - three times the support seen in the late 1970s. Communication with the public is a central factor in the acceptance of the future use of nuclear power to generate energy [10].

Current support for nuclear power is uneven. A recent study in the European Union showed relatively low support for nuclear power, even among the nations most concerned about climate change [11]. In the developed counties of Asia public opinion is satisfied with the current share of power coming from nuclear energy and there is no strong sentiment to increase or decrease its share [2]. In contrast, support for nuclear power has been increasing in China and the USA [12]. Currently 24 countries are considering building nuclear reactors. 


\section{Background}

Most students entering college in the USA bring with them a set of mores that have been strongly influenced by their parents and high school peers. Unfortunately, many of these beliefs are not strongly rooted in science. Consequently, it is important to expose students to an introductory environmental science class that is based on the principles of the scientific method rather than the advocacy of stances on specific environmental issues.

Consequently, an introductory environmental science class was developed in 1993 at the University of Idaho. The purpose of this course was to teach students about environmental issues from a science basis rather than the bias of advocacy. In this way students could base their responses and actions to issues on science rather than bias or simple beliefs. The 18 environmental issues covered in this course include: (1) population growth, (2) food resources, (3) ecology, (4) biodiversity, (5) non-renewable energy resources, (6) renewable energy resources, (7) nuclear energy, (8) water quantity, (9) surface water quality, (10) drinking water quality, (11) outdoor air pollution, (12) indoor air pollution, (13) acid rainfall, (14) ozone depletion, (15) global warming, (16) solid waste disposal, (17) sewage disposal, and (18) hazardous waste.

The teaching methodology of this course was evaluated in two different ways. First, at the end of each term enrolled students completed a course evaluation to indicate if they thought that there was any bias in the way issues were presented. The second instrument consisted of 32 statements about environmental issues that students were asked to strongly agree, agree, disagree, strongly disagree or have no opinion about. This second instrument was given to students during the first day of class and again during the fifteenth week of the term so that student opinion change could be measured. This change in student opinion would be attributable to unbiased scientific education about environmental issues. This instrument allowed the instructor (senior author) and the Environmental Science Program at the University of Idaho to assess learning outcomes and to measure student opinions about environmental issues.

Consequently, the purpose of this paper is to measure student opinions about the safety and future potential of nuclear energy in the world as affected by mores developed prior to entering college, mores developed in college and the effect of unbiased science presented using the principles of the scientific method in an introductory environmental science class over a relatively short 15 -week period.

\section{Methodology}

A survey instrument with 32 statements about specific environmental issues was developed in 1993. This instrument contained the following two statements specific to nuclear energy:

"Nuclear energy is a serious problem from an environmental standpoint"

"Nuclear energy is preferable to the use of fossil fuels" 
For each of the 32 survey statements the students were instructed to circle one of the following answers: SA (strongly agree), A (agree), $\mathrm{N}$ (neutral or no opinion), D (disagree) or SD (strongly disagree). This survey instrument was included in the syllabus packet that students received on the first day of class. In addition to the survey answers students provided information about their major, gender and year in college. Students turned in the completed survey questionnaire on their way out of the classroom. Students again received the same survey during the fifteenth week of the semester. Again the completed survey instrument was collected at the end of the class period.

The same survey procedure was repeated for 40 straight semesters from fall 1993 through spring 2012. During this period of time over 6,340 students completed the two surveys. The average number of completed surveys was 165 per semester. Because of the way this study was conducted it was estimated that the student response rate exceeded $94 \%$.

The data from each completed survey were summarized and a statistical analysis was performed to measure opinion change. The collective 40 semester data sets were analyzed using SAS and where appropriate, t-tests and orthogonal contrast comparisons were used to evaluate the interactions of gender, sampling year, student major and year in college.

\section{Results and discussion}

The two survey questions discussed in this paper were asked of students who took Environmental Science 101 every semester from fall term 1993 through spring 2012. This class was taught every semester during this period for a total of 40 times. Enrollment ranged from a low of 27 in fall 1993, the first time this class was taught, to a peak of 367 in spring 2010. Students took this class for one of the three following reasons: (1) general interest, (2) requirement for their major, or (3) to fulfill the university science requirement required of all students. During this 20-year period over 6,300 students answered the two survey questions contained in this paper during the first and fifteenth weeks of the semester.

\subsection{Nuclear power as a problem}

The summary results of student reactions to the statement "Nuclear power is a serious problem from an environmental standpoint" are shown in Table 1. When averaged over the 20-year study, $46.7 \%$ of the students came into the class believing that nuclear power was a serious environmental problem. However, by the last week of the semester fewer than $32 \%$ of the students felt that nuclear power was a serious problem. This change in attitude was statistically significant $(p=0.0001)$. Perhaps even more insightful was that the percentage of students disagreeing with the survey statement increased from 18.6 to $42.4 \%$. In addition, the percentage of students neutral to the survey statement also significantly declined by the end of the course $(\mathrm{p}=0.003)$. 
Table 1: University of Idaho student reactions to the statement "Nuclear power is a serious problem from an environmental standpoint."

\begin{tabular}{lll}
\hline Response & Before (week 1), \% & After (week 15), \% \\
\hline Strongly agree/agree & 46.7 & 31.4 \\
Strongly disagree/disagree & 18.6 & 42.4 \\
Neutral & 34.7 & 26.2 \\
\hline
\end{tabular}

$\mathrm{n}=6,318 ; \mathrm{p}=0.00001$

Even though a relatively high percentage of students entering this class believed that nuclear power is a serious environmental problem, between 199394 and 2005-2009 the percentage calling this a serious problem declined (Table 2). The numbers bumped up a little in 2010-2012 presumably due to the Fukushima accident in Japan. By the end of the semester between 11 and 16\% less students cited nuclear power as a serious problem. This significant decline occurred for all years and was probably the result of using the scientific method in class to evaluate the pros and cons of nuclear power.

Table 2: $\quad$ The influence of survey year on the University of Idaho students agreeing with the statement "Nuclear power is a serious problem from an environmental standpoint."

\begin{tabular}{lll}
\hline Survey years & Before (week 1), \% & After (week 15), \% \\
\hline $1993-1994$ & 51.6 & 38.4 \\
$1995-1999$ & 49.0 & 35.1 \\
$2000-2004$ & 46.6 & 29.6 \\
$2005-2009$ & 41.6 & 24.4 \\
$2010-2012$ & 44.6 & 33.1 \\
All years & 46.7 & 31.4 \\
\hline $\mathrm{n}=6,318 ; \mathrm{p}=0.00001$ & &
\end{tabular}

Year in college also had a significant impact on the view that nuclear power is a serious environmental problem $(\mathrm{p}=0.00001)$ (Table 3$)$. In general, younger college students were more likely to consider nuclear power a serious problem than their older fellow college students. These observations were supported by data at both weeks one and 15. Again, after taking the class students were 13 to $15 \%$ less likely to condemn nuclear power.

Female college students were more likely to consider nuclear power a serious environmental problem than males both at the beginning and end of the environmental science class $(p=0.0001)$ (Table 4). Females were $10.7 \%$ more likely to be pessimistic at the beginning of class and $6.9 \%$ more likely at the end of class to consider nuclear power a serious problem than males. As noted with the other factors discussed education about nuclear power had a significant impact on student views. 
Table 3: The influence of year in college on the University of Idaho students agreeing with the statement "Nuclear power is a serious problem from an environmental standpoint."

\begin{tabular}{ccc}
\hline Year in college & Before (week 1), \% & After (week 15), \% \\
\hline 1 & 49.2 & 34.2 \\
2 & 45.2 & 30.1 \\
3 & 42.6 & 28.2 \\
4 & 40.1 & 26.5 \\
All years & 46.7 & 31.4 \\
\hline
\end{tabular}

$\mathrm{n}=6,321 ; \mathrm{p}=0.00001$

Table 4: The influence of gender on the University of Idaho students agreeing with the statement "Nuclear power is a serious problem from an environmental standpoint."

\begin{tabular}{lll}
\hline Gender & Before (week 1), \% & After (week 15), \% \\
\hline Male & 41.4 & 28.3 \\
Female & 52.1 & 35.2 \\
All respondents & 46.7 & 31.4 \\
\hline
\end{tabular}

$\mathrm{n}=6,290 ; \mathrm{p}=0.00001$

Table 5: $\quad$ The influence of major on the University of Idaho students agreeing with the statement "Nuclear power is a serious problem from an environmental standpoint."

\begin{tabular}{lll}
\hline Major & Before (week 1), \% & After (week 15), \% \\
\hline Agriculture & 36.0 & 20.1 \\
Architecture & 48.5 & 30.3 \\
Business & 41.1 & 26.1 \\
Education & 60.1 & 50.4 \\
Engineering & 40.1 & 18.6 \\
Forestry & 49.4 & 32.1 \\
General Studies & 51.1 & 38.4 \\
Humanities & 54.6 & 44.3 \\
Science & 44.2 & 24.2 \\
Social Science & 56.5 & 46.2 \\
All respondents & 46.7 & 31.4 \\
\hline
\end{tabular}
$\mathrm{n}=6,246 ; \mathrm{p}=0.00001$

Educational major had a significant impact on the belief that nuclear power is a serious environmental problem (Table 5). The majors could be broken down into four general groupings. Students majoring in agriculture, business and 
engineering were the least likely to enter the course believing that nuclear power is a serious environmental problem (36.0 to 40.1\%). Students majoring in science were the next group least likely to consider nuclear power a serious environmental problem (44.2\%). About half of the students in the third group majoring in architecture, forestry and general studies had the preconceived notion that nuclear power is a serious problem (48.5 to $51.1 \%$ ). A majority of students majoring in education, humanities and social sciences came into this class believing that nuclear power is a serious problem (54.6 to 60.1\%). Regardless of major by the end of the semester all major categories of students were much less likely to consider nuclear power a serious environmental problem $(\mathrm{p}=0.0001)$.

\subsection{Nuclear power is preferable to fossil fuels}

Young adults with little science background generally consider traditional fossil fuels safe and nuclear energy to be less safe. This observation has been confirmed 40 times (every semester) in the freshman environmental science class at the University of Idaho (Table 6). Approximately $30 \%$ of the 6,318 surveyed students thought that nuclear power was preferable to the use of fossil fuels at the beginning of the term; however, this percentage almost doubled to $60.1 \%$ by the end of the term $(p=0.00001)$. There is little doubt the relationship between carbon dioxide emissions and the burning of fossil fuels caused this opinion shift. It is interesting to note that student neutrality about this statement decreased from 57.3 to $23.3 \%$ by the end of the course.

Table 6: University of Idaho student reactions to the statement "Nuclear energy is preferable to the use of fossil fuels."

\begin{tabular}{lll}
\hline Response & Before (week 1), \% & After (week 15), \% \\
\hline Strongly agree/agree & 34.6 & 63.4 \\
Strongly disagree/disagree & 12.6 & 16.6 \\
Neutral & 52.8 & 20.0
\end{tabular}

$\mathrm{n}=6,318 ; \mathrm{p}=0.00001$

Survey year affected student agreement with the statement "Nuclear energy is preferable to the use of fossil fuels" (Table 7). In general, agreement at the beginning of the semester ranged from 33.6 to 35.3\% between 1995 and 2012 but was statistically similar $(\mathrm{p}=0.23)$. Conversely, agreement increased from $52.4 \%$ in $1993-94$ to $74.2 \%$ in $2005-2009$ at the end of the semester $(p=0.0004)$. At the end of the semester agreement that nuclear power was preferable between the 2005-2009 and 2010-2012 groups dropped from 74.2 to $64.1 \%$, presumably due to the Fukushima accident in 2011 ( $\mathrm{p}=0.0006$ ).

First year college students were less likely to consider nuclear energy preferable to fossil fuels at both the beginning and at the end of the course than 
second, third and fourth year college students $(\mathrm{p}=0.0001)$ (Table 8). Despite these differences due to year in college the preferences for nuclear energy almost doubled by the end of the semester for all groups.

Table 7: The influence of survey year on the University of Idaho students agreeing with the statement "Nuclear energy is preferable to the use of fossil fuels."

\begin{tabular}{lll}
\hline Survey years & Before (week 1), \% & After (week 15), \% \\
\hline $1993-1994$ & 28.6 & 52.4 \\
$1995-1999$ & 34.4 & 63.0 \\
$2000-2004$ & 35.3 & 66.8 \\
$2005-2009$ & 33.6 & 74.2 \\
$2010-2012$ & 35.2 & 64.1 \\
All years & 34.6 & 63.4 \\
\hline
\end{tabular}

$\mathrm{n}=6,307 ; \mathrm{p}=0.00001$

Table 8: The influence of year in college on the University of Idaho students agreeing with the statement "Nuclear energy is preferable to the use of fossil fuels."

\begin{tabular}{cll}
\hline Year in college & Before (week 1), \% & After (week 15), \% \\
\hline 1 & 28.4 & 57.6 \\
2 & 34.2 & 64.0 \\
3 & 36.6 & 64.9 \\
4 & 35.6 & 67.4 \\
All years & 34.6 & 63.4 \\
\hline
\end{tabular}

$\mathrm{n}=6,305 ; \mathrm{p}=0.00001$

Males were much more likely than females to favor nuclear power over fossil fuels at the beginning ( 43.3 vs. $25.7 \%$ ) and completion ( 78.2 vs. $47.5 \%$ ) of the environmental science course $(\mathrm{p}=0.00001)$ (Table 9$)$. The environmental science course increased the male rate of nuclear power preference over fossil fuels by $34.9 \%$, while female preferences for nuclear power increased by a more modest $21.8 \%$. This gender difference is wide and cannot be attributed to class size since $52 \%$ of the 6,301 sampled students were female.

Table 9: The influence of gender on the University of Idaho students agreeing with the statement "Nuclear energy is preferable to the use of fossil fuels."

\begin{tabular}{lll}
\hline Gender & Before (week 1), \% & After (week 15), \% \\
\hline Male & 43.3 & 78.2 \\
Female & 25.7 & 47.5 \\
All respondents & 34.6 & 63.4 \\
\hline
\end{tabular}

$\mathrm{n}=6,301 ; \mathrm{p}=0.00001$ 
College major significantly affected the response to the statement "nuclear energy is preferable to the use of fossil fuels" ( $p=0.00001)$ (Table 10). Even though less than half the surveyed students of each major initially favored the preference of nuclear energy over fossil fuels, major was significant. The initial survey showed that more than $40 \%$ of the agriculture, business, engineering and science majors felt that nuclear energy was preferable to fossil fuels. Conversely, less than $25 \%$ of students majoring in education, humanities and social sciences felt this way. By the end of the class a majority of all students except those majoring in education, humanities and social sciences favored nuclear power over the use of fossil fuels. The seriousness of global warming issue is responsible to a large degree for student willingness to take another look at this energy source.

Table 10: The influence of major on the University of Idaho students agreeing with the statement "Nuclear energy is preferable to the use of fossil fuels."

\begin{tabular}{lll}
\hline Major & Before (week 1), \% & After (week 15), \% \\
\hline Agriculture & 46.2 & 70.6 \\
Architecture & 31.6 & 61.2 \\
Business & 43.8 & 78.1 \\
Education & 20.4 & 39.4 \\
Engineering & 42.4 & 79.4 \\
Forestry & 35.3 & 63.0 \\
General Studies & 30.4 & 60.0 \\
Humanities & 21.4 & 46.2 \\
Science & 44.4 & 71.1 \\
Social Science & 23.7 & 42.7 \\
All respondents & 34.6 & 63.4 \\
\hline
\end{tabular}
$\mathrm{n}=6,237 ; \mathrm{p}=0.00001$

\section{Conclusions and recommendations}

The unbiased presentation of the pros and cons associated with the use, safety and potential of nuclear energy in the freshman level introductory environmental science class resulted in a significant increase in acceptance by college students. The term unbiased in this paper simply means that data was presented on both sides of the nuclear power issue. Lecture presentations tried to present a balanced view of this energy source. For instance if six points were made that showed the positive aspects of nuclear power, six points would also be made about current shortfalls of nuclear power. Say that this was an unbiased presentation of information may be going too far; however, it may be more correct to say that the information was presented in a measured balanced manner such that the students could not tell if the course lecturer approved or disapproved of the use of nuclear energy. 
Most of the surveyed students entered college with negative perceptions of nuclear energy; however, the unbiased science education approach using the scientific method significantly changed student views. The current concern about global warming and consequent climate change resulting from greenhouse gas emissions through the use of coal, oil and natural gas makes nuclear energy a viable alternative that many college age adults in the USA are willing to accept.

In general $46.7 \%$ of students considered nuclear power a serious problem at the beginning of the course; however, at the end of the term less than $32 \%$ of students still held their initial negative opinion. In addition, a majority of students changed from indicating that fossil fuels were preferable to nuclear energy at the beginning of the course to a significant majority favoring or at least saying that nuclear power was no worse than fossil fuels at the conclusion of the term. Student major, year in college, and year sampled also had an impact on student answers. The most significant finding of this study was that once students were educated about both the pros and cons of using nuclear energy they were more receptive to view the nuclear power option more favorably.

\section{Acknowledgements}

The authors would like to acknowledge the 6,300 undergraduate students at the University of Idaho who took part in this survey process.

\section{References}

[1] Pidgeon, N. and Demski, C.C., From nuclear to renewable: Energy system transformation and public attitudes. Bulletin of the Atomic Scientists, 68:41$51,2012$.

[2] Liao, S., Tseng, W. and Chen, C., Eliciting public preference for nuclear energy against the backdrop of global warming. Energy Policy, 38:7054$7069,2010$.

[3] Truelove, H.B. and Greenberg, M., Who has become more open to nuclear power because of climate change? Climate Change, 116:389-409, 2013.

[4] Choi, Y.S., Kim, J.S. and Lee, B.W., Public's perception and judgment on nuclear power. Annals of Nuclear Energy, 27:295-309, 2000.

[5] Poumadere, M., Bertoldo, R. and Samadi, J., 2011. Public perceptions and governance of controversial technologies to tackle climate change: Nuclear power, carbon capture and storage, wind and geoengineering. WIREs Climate Change, 2:712-727, 2011.

[6] Visschers, V.H.M. and Siegrist, M., How a nuclear power plant accident influences acceptance of nuclear power: results of a longitudinal study before and after the Fukushima disaster. Risk Analysis, 33:333-346, 2013.

[7] Rosa, E.A. and Dunlap, R.E., 1994. Nuclear power: Three decades of public opinion. Public Opinion Quarterly, 58:295-324, 1994.

[8] Ohnishi, T., Effect of nuclear education on public attitude. Journal of Nuclear Science and Technology 32:1027-1038, 1995. 
[9] Bisconti, A.S., Why Americans support nuclear energy - development and characteristics of public opinion in the US. ATW-Internationale Zeitschrift fur Kernenergie, 48:456, 2003.

[10] Visschers, V.H.M., Keller, C. and Siegrist, M., Climate change benefits and energy supply benefits as determinants of acceptance of nuclear power stations: Investigating an explanatory model. Energy Policy, 39:3621-3629, 2011.

[11] Pampel, F.C., Support for nuclear energy in the context of climate change: Evidence from the European Union. Organization and Environment, 24:249-268, 2011.

[12] Ahearne, J.F., Prospects for nuclear energy. Energy Economics, 33:572$580,2011$. 